OPEN ACCESS

Edited by:

Ramesh L. Gardas,

Indian Institute of Technology

Madras, India

Reviewed by:

Guang Zhao,

China University of Petroleum

(Huadong), China

Naved I. Malek,

Sardar Vallabhbhai National Institute

of Technology Surat, India

*Correspondence:

Tongjing Liu

Itjcup@cup.edu.cn

Specialty section

This article was submitted to

Physical Chemistry and Chemical

Physics,

a section of the journal

Frontiers in Chemistry

Received: 15 April 2020

Accepted: 30 July 2020

Published: 14 October 2020

Citation:

Hou G, Zhao W, Jia Y, Yuan X, Zhou J,

Liu T and Hou J (2020) Field Application of Nanoscale Polymer Microspheres for In-Depth Profile Control in the Ultralow Permeability Oil

Reservoir. Front. Chem. 8:805.

doi: 10.3389/fchem.2020.00805

\section{Field Application of Nanoscale Polymer Microspheres for In-Depth Profile Control in the Ultralow Permeability Oil Reservoir}

\author{
Ganggang Hou ${ }^{1}$, Wenyue Zhao ${ }^{1}$, Yuqin Jia ${ }^{2}$, Xinyu Yuan ${ }^{1}$, Jian Zhou ${ }^{1,3}$, Tongjing Liu ${ }^{1 *}$ and \\ Jirui Hou ${ }^{1}$ \\ ${ }^{1}$ Unconventional Petroleum Research Institute, China University of Petroleum, Beijing, China, ${ }^{2}$ Oil \& Gas Technology \\ Research Institute of Changqing Oilfield Company, Xi'an, China, ${ }^{3}$ BeiJing Jinshi Liyuan Science Co., Ltd., Beijing, China
}

Much research has been carried out on nanoscale polymer microspheres (PMs) in laboratories in recent years. However, there are limited reports on the practical application of nanoscale PMs in ultralow permeability reservoirs. This paper reports a field application case of nanoscale PMs for in-depth profile control in the ultralow permeability oil reservoir. In the paper, the characteristics of the reservoir and the problems faced during development are analyzed in detail. Then, the PMs with calibration diameters of $300 \mathrm{~nm}$ and $800 \mathrm{~nm}$ are researched by evaluation experiments, and are selected for in-depth profile control in the ultralow permeability oil reservoir. Finally, according to the effect of the pilot application, the performance of PMs is evaluated, and a more suitable size for the pilot test reservoir is determined. The experiment's results show that the PMs have a good capacity for swelling and plugging. For the PMs with a calibration diameter of $300 \mathrm{~nm}$, the final equilibrium swelling ratio is $56.2 \mathrm{~nm} \cdot \mathrm{nm}^{-1}$, and the maximum resistance coefficient and the blocking rate after swelling are 3.7 and $70.31 \%$, respectively. For the PMs with a calibration diameter of $800 \mathrm{~nm}$, the final equilibrium swelling ratio is 49.4 $\mathrm{nm} \cdot \mathrm{nm}^{-1}$, and the maximum resistance coefficient the blocking rate after swelling are 3.5 and $71.42 \%$, respectively. The performance evaluation results show that nanoscale PMs can be used for in-depth profile control in the ultralow permeability oil reservoir. After the application of PMs in the pilot test area, the average water cut decreased by $10.4 \%$, the average liquid production of single well-increased by $0.9 \mathrm{t} / \mathrm{d}$, and the average thickness of the water-absorbing layer increased by $1.77 \mathrm{~m}$. Comparing the dynamic data variation of well-groups using the PMs with the calibration diameter as $800 \mathrm{~nm}$ and the calibration diameter as $300 \mathrm{~nm}$, it indicates that, for the pilot test area, PMs with a calibration diameter of $300 \mathrm{~nm}$ are more suitable than PMs with a calibration diameter of $800 \mathrm{~nm}$.

Keywords: nanoscale polymer microspheres, ultralow permeability oil reservoir, practical application, performance evaluation, in-depth profile control 


\section{INTRODUCTION}

The demand for petroleum energy plays a vital role in global energy supply (Asif and Muneer, 2007). Water-flooding is the most common development method in the primary or secondary oilfield development, because of its convenient application and low cost (Afeez et al., 2018). However, with the development of water-flooding, the heterogeneity of reservoirs will become more and more serious (Sang et al., 2014). In the later stage of oilfield development, the difficulty of water-flooding is increasing, and the efficiency of water-flooding is decreasing (Ji et al., 2017). This phenomenon results in lots of oil remaining in the reservoir, which cannot be produced by conventional development methods (Pu et al., 2016; AfzaliTabar et al., 2017). To combat this, enhanced oil recovery (EOR) technology can be used to develop this oil. However, there are so many EOR methods, such as chemical flooding and gas flooding, and which method should be used in the oilfield, depends on the characteristics and main problems of the reservoir.

Low or ultralow permeability oil reservoirs are mainly characterized by their low porosity, low permeability, small radius of pore-throat, and widespread distribution of natural fractures (Lin et al., 2015; Liu et al., 2018). The characteristics of low permeability reservoirs makes it necessary to use artificial fracturing technology during the development of the reservoir. The artificial fractures formed by artificial fracturing can connect with natural fractures, thus the development efficiency of low permeability oil reservoirs will significantly increase (Fletcher et al., 1992; Diwu et al., 2018). However, the permeability of these fractures will gradually become higher after the long-term injection of water, and that will improve the heterogeneity of low permeability oil reservoirs (Zhao et al., 2018). This in turn leads to low permeability oil reservoirs facing many problems, such as rapid breakthrough of water, non-uniform water-absorbing of injection wells, and low water flooding efficiency (Liu et al., 2018). Profile control technology is considered to be an effective method to solve such problems (Jia et al., 2018).

Profile control technology can be divided into conventional profile control and in-depth profile control, according to the plugging positions (Dai et al., 2010). The conventional profile control method mainly plugs the high-permeability channels near the well, while the in-depth profile control method mainly plugs the high-permeability channels in the deep part of the reservoir (Zhao et al., 2014). For the ultralow permeability oil reservoir, in-depth profile control is more suitable than the conventional profile control. This is because in the ultralow permeability oil reservoir, fractures including the artificial fractures and natural fractures are distributed widely. After the near well is plugged, the subsequent injection water will flow around these areas and then return to the high-permeability channels (Zhou et al., 2017). A key component of the in-depth profile control technology of ultralow permeability oil reservoirs is to ensure that the agent can reach the deep part of the reservoir and effectively plug the high-permeability channels (Zhang and Zhou, 2008; Jia et al., 2019). However, this is impossible for most conventional profile control agents, as they usually cannot flow through the small pores and throat (Li et al., 1993; Tu and Wang,
2011). The nanoscale polymer microspheres (PMs) have attracted more and more attention as in-depth profile control agents in recent years (Wu et al., 2018).

PMs are a viscoelastic plugging agent with a 3-D structure that can absorb much more water as compared to their own mass and that make it hard to release the absorbed liquids even under high pressure (Yang et al., 2017). However, these characteristics are not enough for practical application in oilfields. They also need to have other excellent properties, such as stability and rheology. Many researchers have done a lot of research on these properties (Kawaguchi, 2000; Kang et al., 2015; Lin et al., 2015; Nandwani et al., 2020). The research results show that the stability of the PMs plays a decisive role in deep profile control (Afeez et al., 2018). If the stability is not good, the PMs will be absorbed in near the well-bore and plug the injection channel near the wellbore; thus, the purpose of in-deep profile control will not be achieved (Dai et al., 2017). In order to obtain PMs with better stability, many types of PMs have been developed (Hua et al., 2014; Mehta et al., 2015; Yang et al., 2017b). All these polymer microsphere systems have shown excellent characteristics in laboratory evaluation studies. However, there are limited reports about their application effect in oilfields, especially in ultra-low permeability reservoirs.

This paper reports on a field application case of nanoscale PMs for in-depth profile control in ultralow permeability oil reservoirs. In the paper, the characteristics and the problems of Block A in the Changqing oilfield are analyzed in detail. Then, the PMs with calibration diameters of $300 \mathrm{~nm}$ and $800 \mathrm{~nm}$ are selected based on the radius distribution of the pore-throat of Block A. For ensuring the swelling and plugging properties of PMs, a hydration swelling experiment and plugging evaluation experiment have been done. Based on the experimental evaluation results, the nanoscale PMs are used in the pilot test area for in-depth profile control. Finally, according to the variation of dynamic data of production wells and injection wells, the performance of PMs in the pilot test area are evaluated.

\section{RESERVOIR BACKGROUND}

\section{Field and Reservoir Description}

The Changqing Oilfield is composed of many oil-producing reservoirs, such as Block $\mathrm{A}$, which is represented by its ultralow permeability. The main production layer of Block $\mathrm{A}$ is the Chang $8_{2}$, and its depth ranges between 2,480 and $2,580 \mathrm{~m}$. The thickness of the oil layer varies with net to gross ratio, but the average thickness of the oil layer is $13.69 \mathrm{~m}$. The porosity and permeability of Block A are obtained from the coring results of 18 wells, and their distribution histograms are shown in Figures 1,2 . The porosity mainly ranges between 5 and $15 \%$, and its average value is $10.02 \%$. The permeability mainly ranges between 0.03 and $3 \mathrm{mD}$, and its average value is $0.68 \mathrm{mD}$. The results of casting thin sections indicate that the pore types of Block A are mainly intergranular pores, as shown in Figure 3. Based on the analysis of mercury injection experimental data, the radius distribution of the pore-throat for Block A mainly ranges between 500 and 7,000 $\mathrm{nm}$. The radius distribution curves 


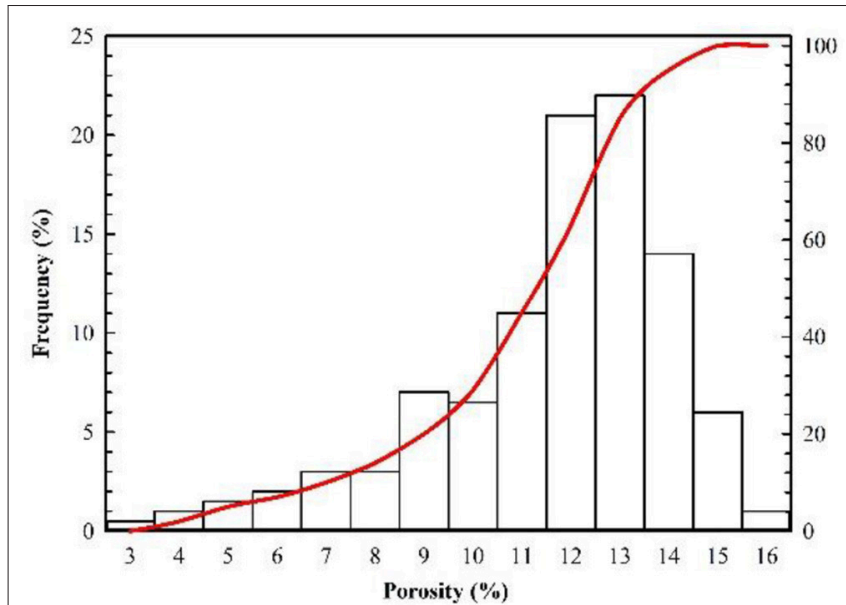

FIGURE 1 | Distribution histograms of porosity.

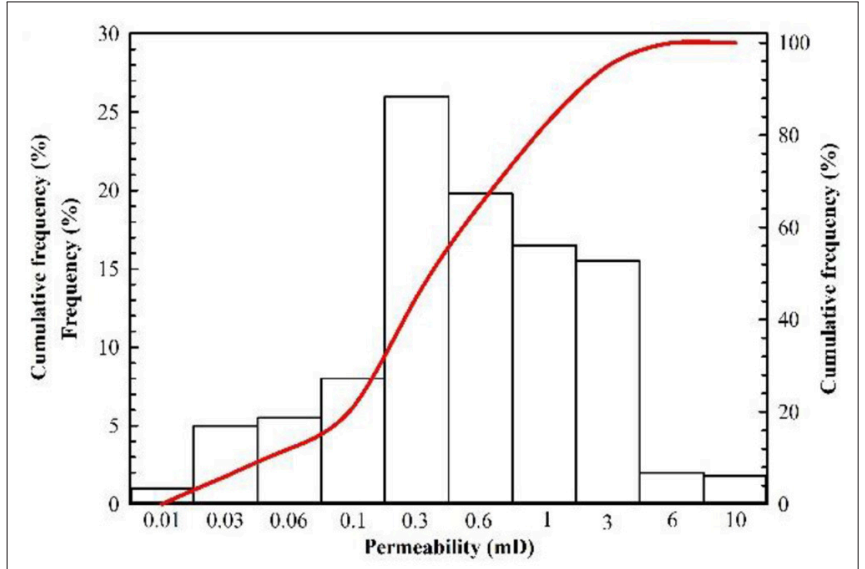

FIGURE 2 | Distribution histograms of permeability.

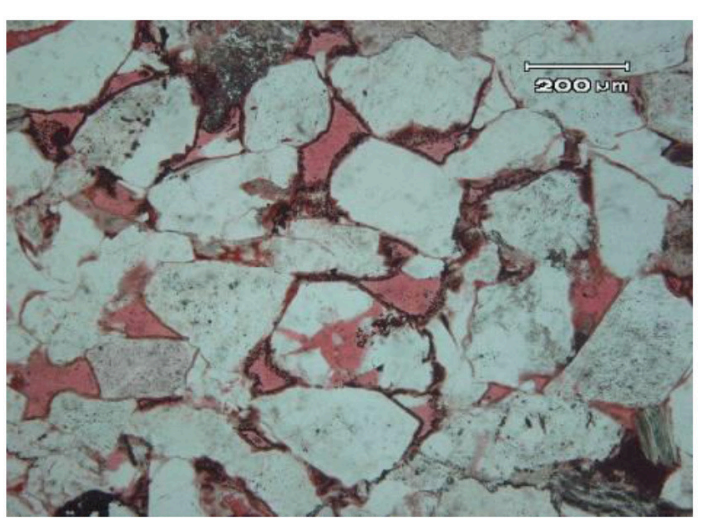

FIGURE 3 | Core casting thin sections sample.

of the pore-throat are shown in Figure 4. The initial pressure and temperature of Block A are $17.5 \mathrm{MPa}$ and $70.4^{\circ} \mathrm{C}$, respectively.

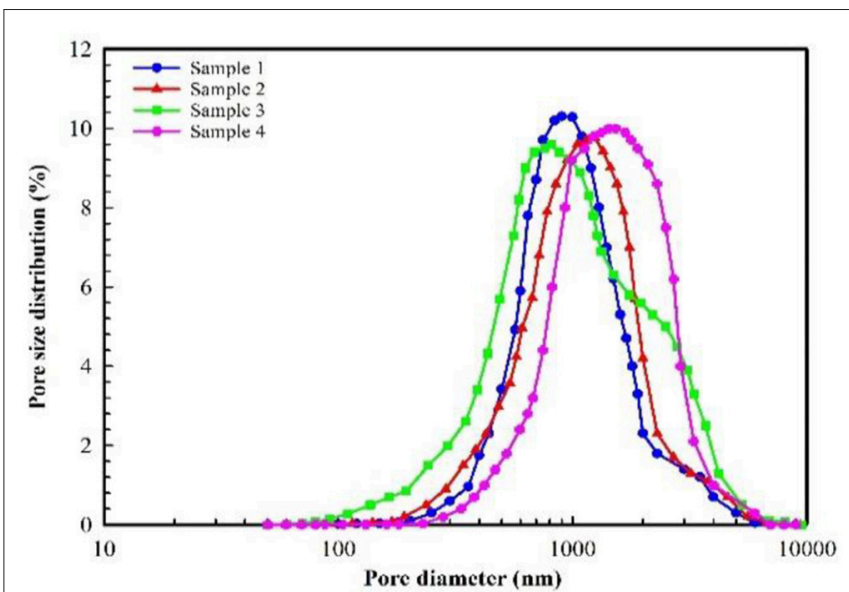

FIGURE 4 | Radius distribution curve of pore-throat.

TABLE 1 | Fluid properties under reservoir conditions.

\begin{tabular}{lc}
\hline Fluid properties & Value \\
\hline Oil density & $0.733 \mathrm{~g} / \mathrm{cm}^{3}$ \\
Oil viscosity & $1.403 \mathrm{mPa} \cdot \mathrm{s}$ \\
Oil volume factor & 1.297 \\
Oil freezing point & $19^{\circ} \mathrm{C}$ \\
Water salinity & $43,000 \mathrm{mg} / \mathrm{l}$ \\
Water type & $\mathrm{CaCl}_{2}$
\end{tabular}

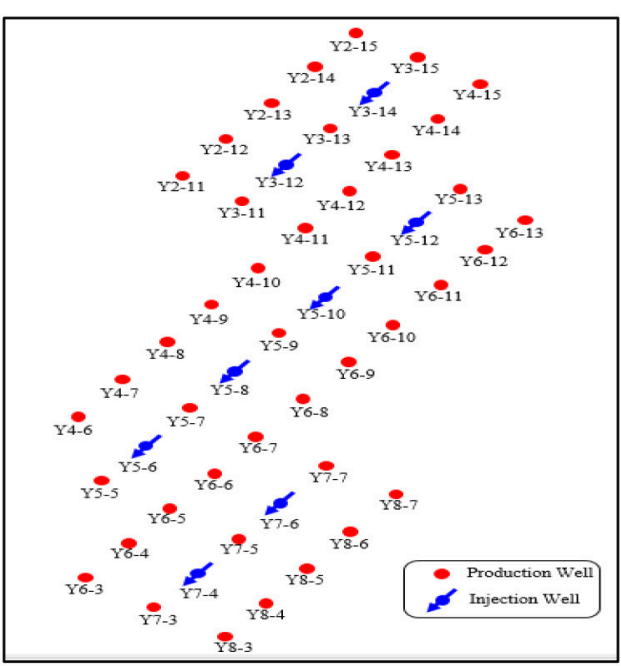

FIGURE 5 | Well-location map for pilot test area

The fluid properties under reservoir conditions are shown in Table 1.

Primary oil production started in 2008 for Block A, but water injection was initiated in 2007 to maintain reservoir pressure. In the early stage of production, the average daily oil production of a single well was $5.92 \mathrm{t} / \mathrm{d}$, and the average water 

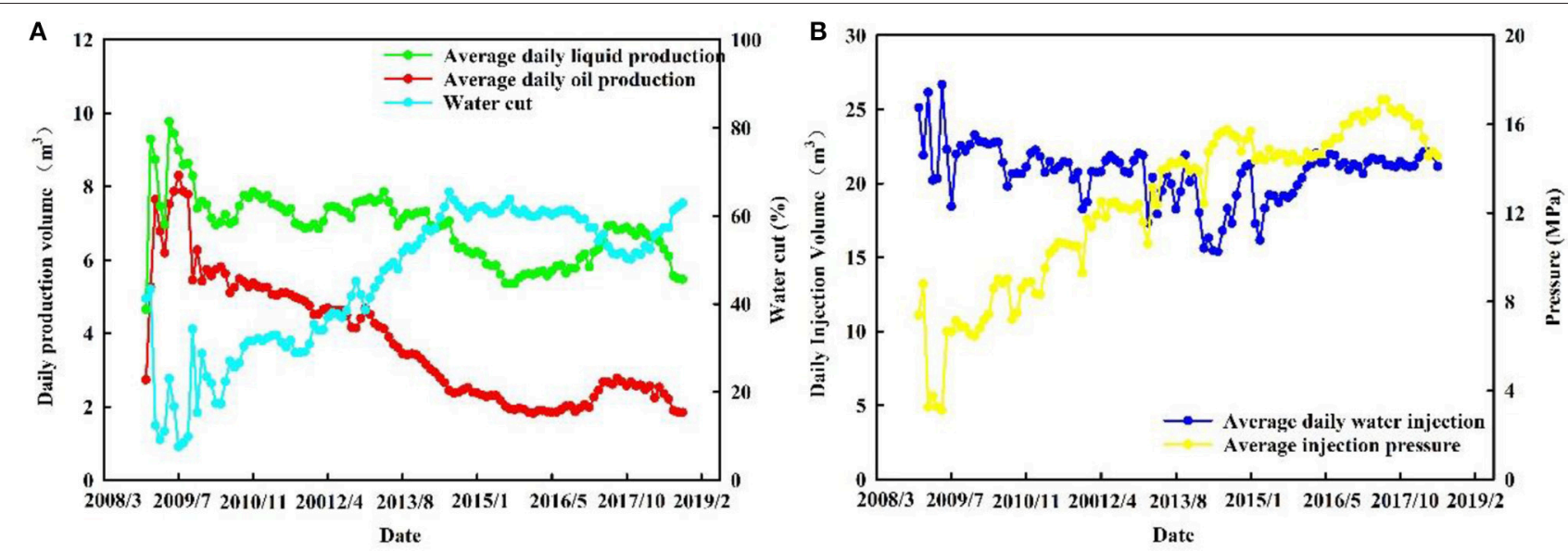

FIGURE 6 | Dynamic data: (A) production dynamic date of oil wells; (B) injection dynamic date of water wells.

cut of a single well was $16.3 \%$. The production dynamic data indicated that at the beginning all the production wells had very good performances. However, with continuing development, the production performance of this block gradually became worse. As of August 2016, the average daily oil production of a single well-dropped to $1.34 \mathrm{t} / \mathrm{d}$, and the average water cut of a single well-increased to $62.3 \%$. The results of water injection profile tests showed that the characteristic of non-uniform waterabsorbing profile was significant, as shown in Figure 6. The development of Block A was facing many problems, such as the rapid rise of water cuts, the rapid decline of oil production, and the poor performance of water- flooding. The application of PMs for in-depth profile control is considered as an effective method to solve these problems.

\section{Pilot Test Area Description}

In order to evaluate the performance of PMs in-depth profile control in the field application, in September 2016, Changqing Oilfield selected eight well-groups, including eight injection wells and 42 production wells, in Block A for a pilot test. The welllocation map and the dynamic data are shown in Figures 5, 6. As of August 2016, in the pilot test the average daily liquid production of a single well was $5.8 \mathrm{t} / \mathrm{d}$, the average daily oil production of a single well was $1.9 \mathrm{t} / \mathrm{d}$, and the average water cut of a single well was $60.6 \%$. The non-uniformity coefficient of liquid production and water cut was 0.66 and 0.45 , respectively. For the injection wells, the average daily injection rate of a single well was $21.4 \mathrm{t} / \mathrm{d}$ and the average injection pressure of a single well was $14.6 \mathrm{MPa}$. The results of a water injection profile test for five injection wells are shown in Figure 13, and they indicate that for the pilot test area the characteristic of non-uniform water absorption profile was significant.

Selecting the appropriate particle size for PMs is the key to the successful application of PMs for in-depth profile control ( $\mathrm{Li}$ et al., 1993; Hua et al., 2013; Wu et al., 2018). If the particle size of PMs is too small, they will directly flow to the production well with the injected water (Sun et al., 2006). If the particle size of
PMs is too large, they will not reach the deep part of the reservoir (Liang et al., 2016). At present, the main method for selecting the particle size of PMs is based on the three-ball bridging theory proposed by Abrans. This theory demonstrates that the plugging rules of suspended solid particles at the pore and throat are as follows: (1) when the particle size is larger than $1 / 7$ of the porethroat diameter, the suspended solid particles can completely plug the pore and throat; (2) when the particle size is $1 / 3$ to $1 / 7$ of the pore-throat diameter, the suspended solid particles can partially enter the reservoir and slightly plug the pore and throat; (3) when the particle size is $<1 / 7$ of the pore-throat diameter, the suspended solid particles can completely enter the reservoir and cannot plug the pore and throat. Therefore, the plugging effect is best when the particle size of the PMs is equal or slightly larger than $1 / 3$ of the pore-throat diameter (Wang et al., 2006; Zeng et al., 2012). In order to achieve the purpose of in-depth profile control, the particle size of PMs cannot be too large, otherwise they cannot enter the deep part of the reservoir. For the pilot test area, the radius distribution of pore- throat mainly ranges between 500 and $7,000 \mathrm{~nm}$. 1/3 of the pore-throat diameter is between 333 and 4,667 $\mathrm{nm}$. Therefore, considering the hydration swelling property, the PMs with a calibration diameter of $300 \mathrm{~nm}$ and $800 \mathrm{~nm}$ were selected for in-depth profile control.

\section{EXPERIMENTAL SECTION}

\section{Materials}

The calibration diameter of PMs used in the experiment were $800 \mathrm{~nm}$ and $300 \mathrm{~nm}$. The main ingredient of PMs is polyacrylamide, which was provided by Changqing Chemical Group Co. The anhydrous ethanol $\left(\mathrm{CH}_{3} \mathrm{CH}_{2} \mathrm{OH}\right.$, purity above 99.5\%) was used as a dispersant for measuring the diameter of PMs before swelling. The composition of the simulated formation water used in this study is shown in Table 2. The natural cores used in this study were obtained from Chang 8 layer. The properties are shown in Table 3. 
TABLE 2 | lonic composition of formation water and simulated formation water.

\begin{tabular}{|c|c|c|c|c|c|c|c|c|}
\hline & Ion & $\mathrm{Na}^{+} / \mathbf{K}^{+}$ & $\mathrm{Ca}^{2+}$ & $\mathbf{M g}^{2+}$ & $\mathrm{Cl}^{-}$ & $\mathrm{SO}_{4}^{2-}$ & $\mathrm{HCO}_{3}^{-}$ & Total \\
\hline \multirow[t]{2}{*}{ Ion content (mg/L) } & Simulated formation water & 8,105 & 7,692 & 31 & 24,667 & 14 & 161 & 40,670 \\
\hline & Formation water & 7,185 & 8,571 & 162 & 2,6679 & 11 & 381 & 42,989 \\
\hline
\end{tabular}

TABLE 3 | Core properties.

\begin{tabular}{lcccc}
\hline Core number & Length/cm & Diameter/cm & Porosity/\% & Permeability $\mathbf{\text { amD }}$ \\
\hline $1 \#$ & 10.005 & 2.515 & 15.31 & 15.9 \\
$2 \#$ & 10.005 & 2.515 & 15.23 & 16.1 \\
$3 \#$ & 10.005 & 2.515 & 14.24 & 16.4 \\
$4 \#$ & 10.005 & 2.515 & 15.19 & 16.0 \\
\hline
\end{tabular}

a Gas log permeability.

\section{Experimental Setup}

The evaluation experiments of PMs were divided into two parts. One was the experiment of particle size measurement, the other was the displacement experiment.

The experiments of particle size measurement were mainly to evaluate the hydration swelling properties of PMs. The main equipment used in these experiments were Ultrasonic Instrument (produced by Tianjin Autoscience Instrument Co., Ltd.) and Nanoparticle Size Analyzer (produced by Beckman Coulter, USA). Ultrasonic Instrument was primarily used to disperse the PMs solution; its ultrasonic frequency and rated power were $40 \mathrm{KHz}$ and $120 \mathrm{~W}$, respectively. Nanoparticle Size Analyzer was mainly used to measure the diameter of PMs; its measure range is $0.6 \mathrm{~nm}-7 \mu \mathrm{m}$. Other equipment, such as thermostats, quartz cuvettes $(10 \mathrm{ml})$, and electromagnetic stirrers, were also used in these experiments.

The displacement experiment was mainly used to evaluate the plugging properties of PMs. The main equipment used in these experiments were the displacement device and the production fluid detecting device. The experimental setup consisted of a syringe pump, core holder, two cylinders, a constant temperature system, and a pressure transducer connected to a desktop computer for continuous recording of the inlet pressure. The schematic of the experimental setup is shown in Figure 7. The syringe pump (Model 260D, Teledyne ISCO, Lincoln, NE) was used to inject fluids at a desired flow rate. Its maximum pressure is $30 \mathrm{MPa}$, and the flow rate ranges from 0.01 to $20 \mathrm{ml} / \mathrm{min}$.

\section{Experimental Procedure Hydration Swelling Experiment}

Nanoparticle Size Analyzer was used to analyze the particle size before and after swelling. The initial particle size was measured in anhydrous ethanol solution at room temperature, while the swollen particle size was measured in the simulated formation water at $70^{\circ} \mathrm{C}$. In the particle size distribution curves, $D_{50}$ was used to express the average particle size of the microspheres before and after swelling. $D_{50}$ is the particle size from the cumulative distribution curve for a probability of $50 \%$. The experimental procedures of hydration swelling properties are summarized as follows:

(1) Take $100 \mathrm{ml}$ of anhydrous ethanol into a beaker and add an appropriate amount of PMs (including 300 and $800 \mathrm{~nm}$ ). Stir it to get the test sample. Then, measure the diameter three times at room temperature, and calculate the average value as the initial particle size.

(2) Disperse PMs (including 300 and $800 \mathrm{~nm}$ ) into the simulated formation water. Put it into the thermostat and record the time as $0 \mathrm{~h}$. Set the temperature of the thermostat to $70^{\circ} \mathrm{C}$. After $24 \mathrm{~h}$, shake the PMs (including 300 and $800 \mathrm{~nm}$ ) solution for $30 \mathrm{~min}$, and measure the diameter three times. Calculate the average value as the particle size after hydration. Measure the diameter continuously until the change of particle size is small.

\section{Plugging Evaluation Experiment}

In order to evaluate the influence of PMs' swelling capacity on the plugging properties, the plugging experiment of PMs (including 300 and $800 \mathrm{~nm}$ ) before and after swelling were conducted, respectively. Pressure was recorded to evaluate plugging properties. In this experiment, the injection concentration, injection amount, and injection rate of PMs (including 300 and $800 \mathrm{~nm}$ ) were $0.3 \%, 0.3 \mathrm{PV}$, and $0.3 \mathrm{ml} / \mathrm{min}$, respectively. The specific experimental steps were as follows:

(1) First, weigh the cores after they are dried in the thermostats. Then weigh them again after saturated formation water. Finally, calculate the core porosity.

(2) Set the temperature of the thermostat to $70^{\circ} \mathrm{C}$. Inject the simulated formation water into the core $1 \#$ at a rate of 0.3 $\mathrm{ml} / \mathrm{min}$ until the pressure is stable, and then record the pressure. Calculate the permeability of the core.

(3) Inject the PMs (including 300 and $800 \mathrm{~nm}$ ) before swelling into the core at a rate of $0.3 \mathrm{ml} / \mathrm{min}$, and record the pressure. Stop injecting the PMs (including 300 and $800 \mathrm{~nm}$ ) when the injection volume reaches $0.3 \mathrm{PV}$.

(4) Inject the simulated formation water again at the same injection rate and record the pressure. End the experiment when the pressure is stable again.

(5) Change the core, and repeat steps 1-4. However, change the PMs (including 300 and $800 \mathrm{~nm}$ ) injected in step 3 to the after swelling.

\section{RESULTS AND DISCUSSION}

\section{Hydration Swelling Experiment Results}

The particle size of PMs before swelling are measured in the condition of anhydrous ethanol solution and room temperature, 


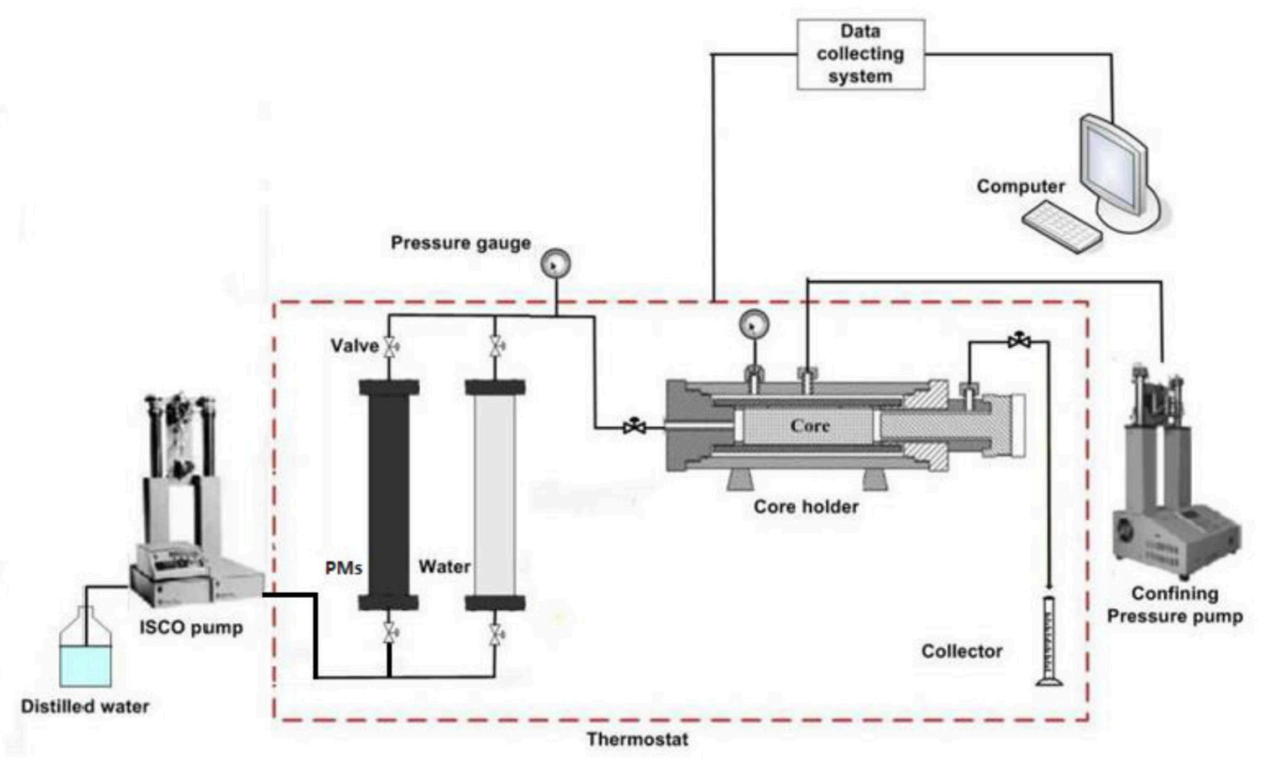

FIGURE 7 | Schematic of the experimental setup.

as shown in Figure 8, and the particle size of PMs after swelling are measured in the condition of simulated formation water at $70^{\circ} \mathrm{C}$, as shown in Figure 9. The three-dimensional (3D) structure of the PMs before swelling can be seen clearly from the environmental scanning electron microscopy (ESEM) image, as shown in Figure 8. As can be seen from the ESEM image, the PMs are spherical particles. The experiment's results show that the particle size of PMs, with calibration diameter as $300 \mathrm{~nm}$ and $800 \mathrm{~nm}$, before swelling is 315 and $784 \mathrm{~nm}$, respectively, and after swelling is 1,205 and $2,798 \mathrm{~nm}$, respectively. The PMs can swell many times due to absorbing a lot of water.

The hydration swelling capacity of PMs can be evaluated using the swelling ratio. The swelling ratio was calculated by Eq (1) (Yang et al., 2017a):

$$
S R=\left(\frac{D_{t}}{d_{0}}\right)^{3}
$$

where $S R$ is the swelling ratio of the PMs (in units of $n m \cdot n m^{-1}$ ), $d_{0}$ is the initial average particle size of the PMs (in units of $n m$ ), and $D_{t}$ is the average particle size of the PMs at swelling time $t$ (in units of $n m$ ).

The dynamic swelling behavior of PMs are measured every $24 \mathrm{~h}$, as shown in Figure 10. For the PMs with a calibration diameter of $300 \mathrm{~nm}$, initially the rate of swelling capacity sharply increases, and then begins to level off. The final equilibrium swelling ratio is $56.2 \mathrm{~nm} \cdot \mathrm{nm}^{-1}$, which takes at least 16 days to achieve. For the PMs with a calibration diameter of $800 \mathrm{~nm}$, initially the rate of swelling capacity slowly increases, then begins to sharply increase, and finally tends to level off. The final equilibrium swelling ratio is $49.4 \mathrm{~nm} \cdot \mathrm{nm}^{-1}$, which takes at least 15 days to achieve. The results of hydration swelling experiments indicate that the PMs, with calibration diameters of 300 and $800 \mathrm{~nm}$, have a good swelling capacity.

\section{Plugging Evaluation Experiment Results}

The plugging capacity of PMs (including 300 and $800 \mathrm{~nm}$ ) before and after swelling was evaluated by water-flooding experiments. The PMs with a calibration diameter of $300 \mathrm{~nm}$ before and after swelling were injected into cores $1 \#$ and $2 \#$. The PMs with a calibration diameter of $800 \mathrm{~nm}$ before and after swelling were injected into cores 3\# and 4\#. Each experiment was divided into three stages: water-flooding (WF), PMs flooding (PMF), and subsequent water-flooding (SWF). At each stage the injection pressure was recorded, as shown in Figure 11. During the displacement experiment, the percolation of the water and PMs conform to Darcy's law. So, the permeability of the core can be calculated by Darcy's law of single phase flow. The resistance coefficient and blocking rate are used to evaluate the plugging capacity of PMs, and this can be calculated using Eq (2) and Eq (3) (Lei and Zheng, 2007):

$$
\begin{array}{r}
F_{r}=\frac{\lambda_{W}}{\lambda_{P}}=\frac{(K / \mu)_{W}}{(K / \mu)_{P}}=\frac{\Delta P_{P}}{\Delta P_{W}} \times \frac{Q_{W}}{Q_{P}} \\
\eta=1-\frac{K_{S W}}{K_{W}}
\end{array}
$$

where $F_{r}$ and $\eta$ are the resistance coefficient and blocking rate, respectively. $K_{W}, K_{P}$, and $K_{S W}$ represent the core permeability of WF, PMF, and SWF, respectively (in units of $\mu m^{2}$ ). $\mu_{w}$ and $\mu_{p}$ are the viscosity of water and PMs (in units of $\mathrm{mPa} \cdot s$ ). $\Delta P_{W}$ and $\Delta P_{P}$ represent the differential pressure of $\mathrm{WF}$ and $\mathrm{PMF}$, respectively (in units of $M P a$ ). $Q_{W}$ and $Q_{P}$ are the injection rate during the process of WF and PMF, respectively (in units of $\mathrm{ml} / \mathrm{min}$ ). 

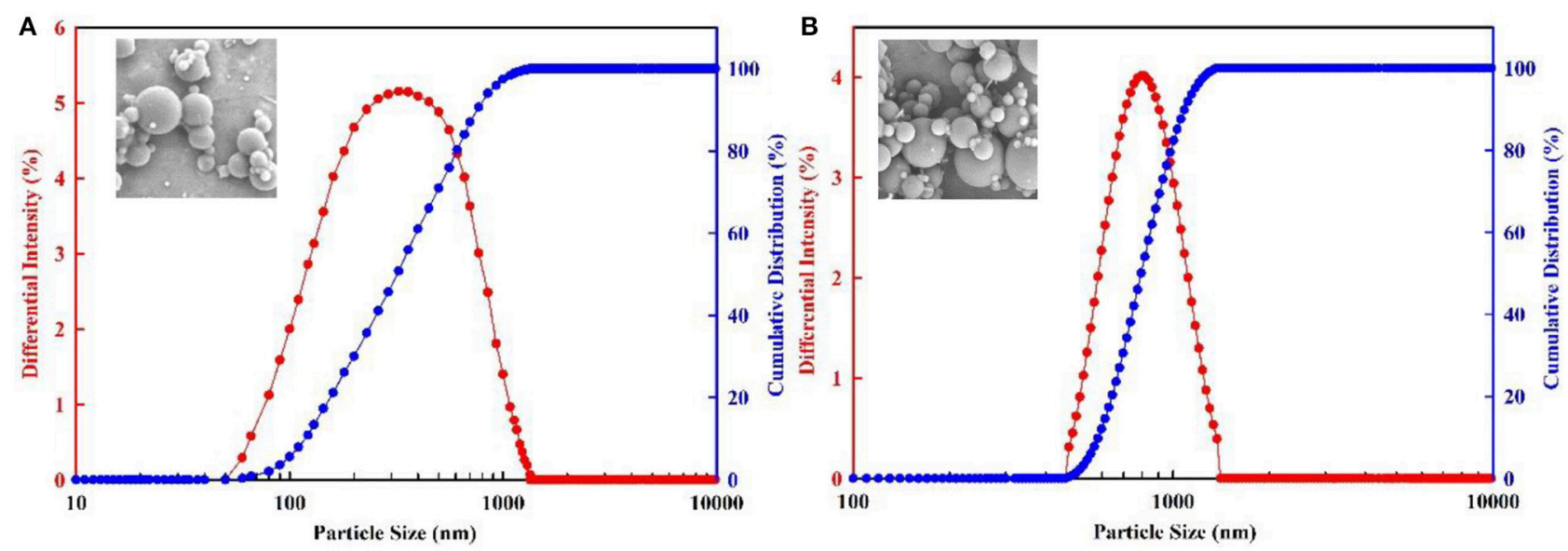

FIGURE 8 | Particle size distribution of PMs before swelling. (A) The calibration diameter is $300 \mathrm{~nm}$; (B) The calibration diameter is $800 \mathrm{~nm}$.
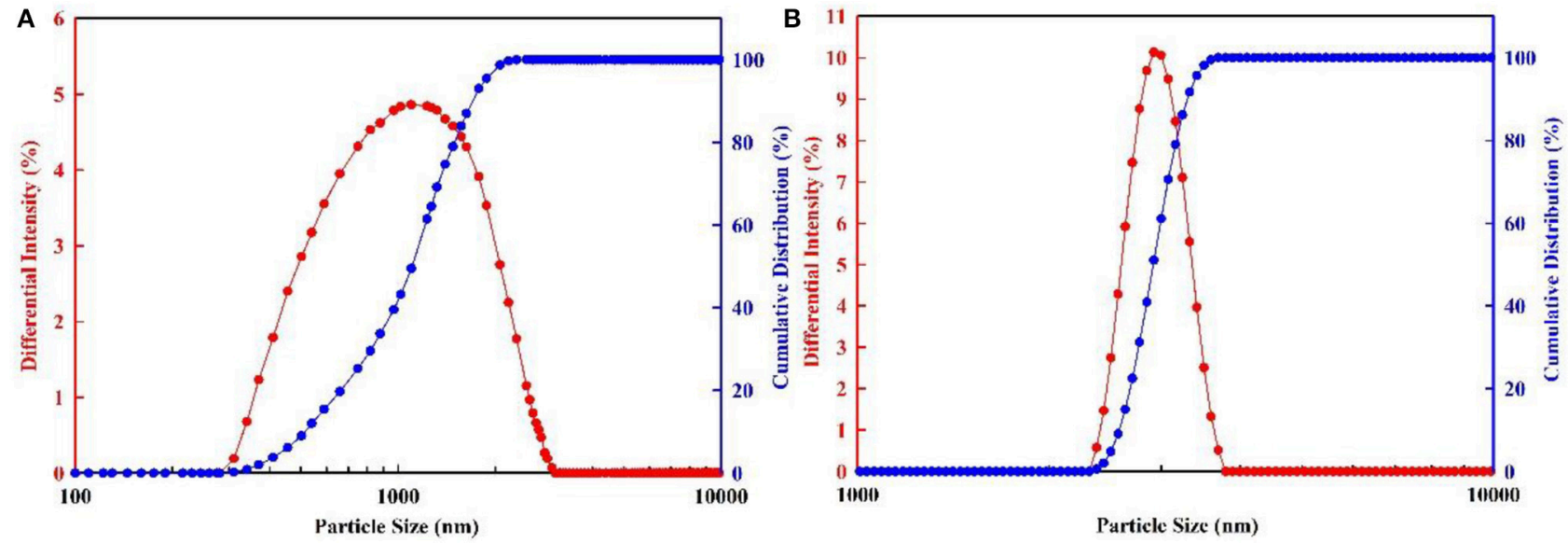

FIGURE 9 | Particle size distribution of PMs after swelling. (A) The calibration diameter is $300 \mathrm{~nm}$; (B) The calibration diameter is $800 \mathrm{~nm}$.

The plugging experiment pressure curve of PMs before and after swelling was plotted, as shown in Figure 11. As can be seen from Figure 11A, for the PMs with a calibration diameter of $300 \mathrm{~nm}$ before swelling, the stable pressure is 85, 90, and $150 \mathrm{KPa}$, respectively, at the stages of WF, PMF, and SWF. Meanwhile, for the PMs after swelling the stable pressure is 95, 100 , and $320 \mathrm{KPa}$, respectively, at the same stage. Therefore, it can be calculated that the maximum resistance coefficient of PMs before and after swelling is 1.7 and 3.7, respectively, and the blocking rate of PMs before and after swelling is 43.33 and $70.31 \%$, respectively. As can be seen from Figure 11B, for the PMs with a calibration diameter of $800 \mathrm{~nm}$ before swelling, the stable pressure is $120 \mathrm{KPa}, 125 \mathrm{KPa}$, and $195 \mathrm{KPa}$, respectively, at the stages of WF, PMF, and SWF. Meanwhile, for the PMs after swelling the stable pressure is 90,95 , and $315 \mathrm{KPa}$, respectively, at the same stage. Therefore, it can be calculated that the maximum resistance coefficient of PMs before and after swelling is 1.6 and 3.5, respectively, and the blocking rate of PMs before and after swelling is 38.46 and $71.42 \%$, respectively. The displacement experiment results show that PMs with calibration diameters of 300 and $800 \mathrm{~nm}$, before and after swelling, have excellent plugging capacity, and the plugging capacity of PMs increases significantly after swelling.

The results of hydration swelling experiments and plugging evaluation experiments indicate that the PMs (including 300 and $800 \mathrm{~nm}$ ) have two significant characteristics. One is that the PMs can swell many times after absorbing water for a long time, and the other is that the plugging capacity of PMs increases significantly after swelling. These two characteristics are essential for in-depth profile control in ultralow permeability oil reservoirs. For the ultralow permeability oil reservoir, the PMs can enter the reservoir with the injected water, and the particle size will gradually increase during the migration process. When PMs reach the deep part of the reservoir, the particle size reaches its maximum, and at this time it also has a better plugging capacity. Therefore, the high-permeability channels can 
be plugged, and the purpose of in-depth profile control can be achieved.

\section{FIELD APPLICATION AND PERFORMANCE EVALUATION}

\section{Field Application}

The experimental evaluation results indicate that the PMs have a good swelling property and plugging property. Therefore, Changqing oilfield decided to apply the PMs in the pilot test area for in-depth profile control to evaluate its performance in the practical application. There were eight well-groups in the pilot test area, of which four well-groups applied the PMs with a calibration diameter of $300 \mathrm{~nm}$, and the other four wellgroups applied the PMs with a calibration diameter of $800 \mathrm{~nm}$. The specific implementation overview is shown in Table 4. For the well groups using the PMs with the calibration diameter of $800 \mathrm{~nm}$, a total of 10 tons of PMs was injected into each injection

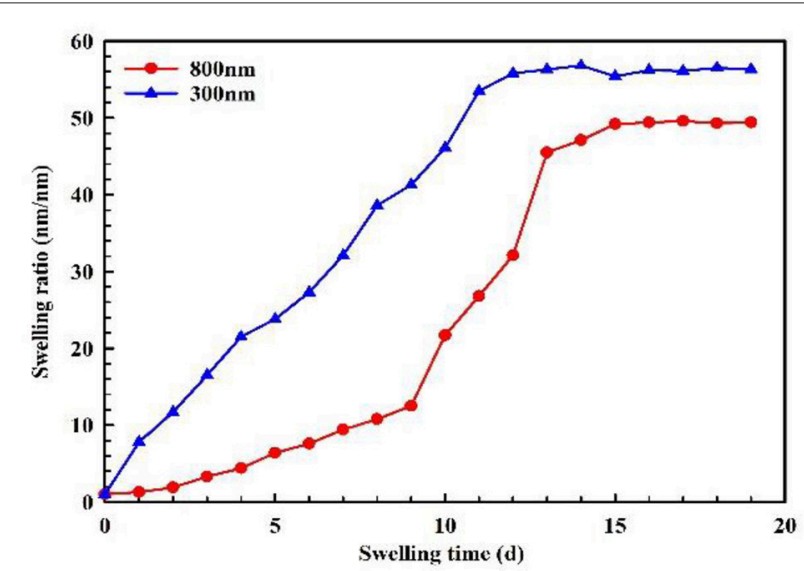

FIGURE 10 | Swelling property of PMs. well from September 2016 to April 2017. The concentration of PMs was the same for every injection well, in which $3 \mathrm{t}$ PMs with a concentration of 5,000 ppm were injected first, and then $7 \mathrm{t}$ PMs with a concentration of 2,000 ppm were injected. For the well-groups using the PMs with a calibration diameter of $300 \mathrm{~nm}$, the injection volume was also 10 tons, but the time was from April 2017 to October 2017. The concentration of PMs was the same, at 5,000 ppm for every injection well. After PMs' injection, the production difference of injection wells and production wells was analyzed to verify the performance of PMs for in-depth profile control.

\section{Performance Evaluation}

\section{Injection Well Performance Evaluation}

After PMs' injection, they will flow into the deep part of the reservoir with the injection water to plug high permeability channels. If the PMs effectively plug high permeability channels, both the injection pressure and the thickness of the waterabsorbing layer will increase under the same work conditions. Specifically for the injection pressure, after the high permeability channel is plugged, the flow resistance will increase at the same injection volume, which will lead to the injection pressure increase according to Darcy's law. Thus, the injection pressure can be used to measure the plugging effect of PMs (Liu et al., 2017). After the PMs' injection, the more the injection pressure increases, the better the plugging effect. For the thickness of the water-absorbing layer, after the high permeability channel is plugged, the subsequent injected water must bypass the plugged area to continue flowing, and that means the thickness of the water-absorbing layer will increase (Jia et al., 2018). So, it also can be used as one of the parameters to measure the plugging effect of PMs. After the PMs' injection, the more the thickness of the water-absorbing layer increases, the better the plugging effect. The thickness of water-absorbing can be measured using the isotopic tracer technique. Its main principle is that radioisotopes flow into the reservoir with injected water and are adsorbed on the surface of the water-absorbing layer. Then, the gamma
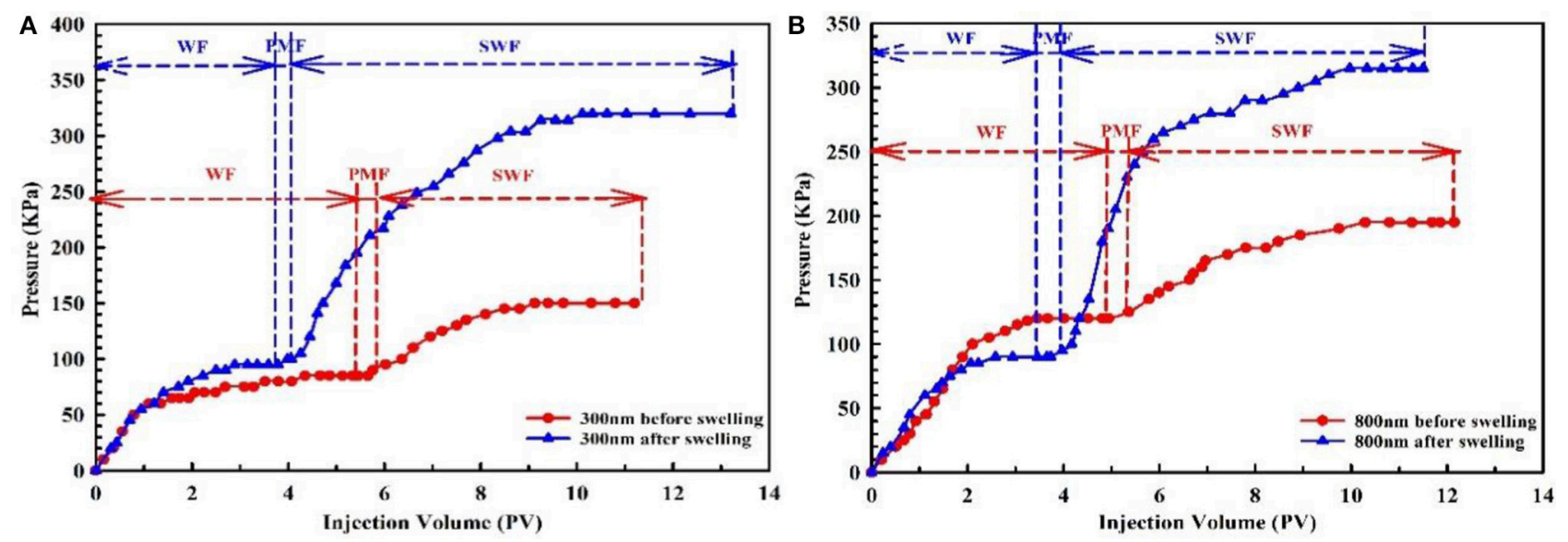

FIGURE 11 | Pressure curve of PMs plugging experiment. (A) The calibration diameter is $300 \mathrm{~nm}$; (B) The calibration diameter is $800 \mathrm{~nm}$. 
TABLE 4 | Detail parameters of PMs injection.

\begin{tabular}{|c|c|c|c|c|c|}
\hline Well & Injection time & Completion time & Particle size (nm) & Concentration & $\operatorname{CIV}^{\mathrm{a}}(\mathrm{t})$ \\
\hline Y3-12 & $2016 / 9$ & $2017 / 4$ & 800 & $5,000 \mathrm{ppm} / 3 \mathrm{t}+2,000 \mathrm{ppm} / 7 \mathrm{t}$ & 10 \\
\hline Y3-14 & $2016 / 9$ & $2017 / 4$ & 800 & $5,000 \mathrm{ppm} / 3 \mathrm{t}+2,000 \mathrm{ppm} / 7 \mathrm{t}$ & 10 \\
\hline Y5-10 & $2016 / 9$ & $2017 / 4$ & 800 & $5,000 \mathrm{ppm} / 3 \mathrm{t}+2,000 \mathrm{ppm} / 7 \mathrm{t}$ & 10 \\
\hline Y5-12 & $2016 / 9$ & $2017 / 4$ & 800 & $5,000 \mathrm{ppm} / 3 \mathrm{t}+2,000 \mathrm{ppm} / 7 \mathrm{t}$ & 10 \\
\hline Y5-6 & $2017 / 4$ & $2017 / 10$ & 300 & 5,000 ppm & 10 \\
\hline Y5-8 & $2017 / 4$ & $2017 / 10$ & 300 & 5,000 ppm & 10 \\
\hline Y7-4 & $2017 / 4$ & $2017 / 10$ & 300 & 5,000 ppm & 10 \\
\hline Y7-6 & $2017 / 4$ & $2017 / 10$ & 300 & 5,000 ppm & 10 \\
\hline
\end{tabular}

${ }^{a}$ Cumulative injection volume.

instrument is used to measure the radiation intensity of the isotope. According to the measurement results, the thickness of the water absorption layer can be calculated by the software of the isotope tracing test (Liu et al., 2020).

For the injection well in the pilot test area, the average daily injection rate of a single well was $21.2 \mathrm{t} / \mathrm{d}$ after PMs' injection. Comparing the injection rate before and after PMs' injection, it showed only a little change. The injection pressure significantly increased for most injection wells, as shown in Figure 12. The average injection pressure of a single well was $16.2 \mathrm{MPa}$, and increased by $1.6 \mathrm{MPa}$ comparing the injection pressure before PMs' injection. The results of the water injection profile test before and after PMs' injection are shown in Figure 13, and the detailed data of the water injection profile test before and after PMs' injection are shown in Table 5. Comparing the results of the water injection profile test before and after PMs' injection, the characteristic of non-uniform water-absorbing was significantly meliorated, and the average thickness of the water-absorbing layer increased from 14.46 to $16.17 \mathrm{~m}$.

For the four injection wells using the PMs with a calibration diameter of $800 \mathrm{~nm}$, the injection pressure was increased after PMs' injection, and its value increased by $2.0,0.7,0.6$, and 2.4 $\mathrm{MPa}$, respectively, as shown in Figure 12A. The average injection pressure of a single well increased by $1.4 \mathrm{MPa}$, and the average thickness of the water-absorbing layer increased by $1.22 \mathrm{~m}$. For the four injection wells using the PMs with the calibration diameter as $300 \mathrm{~nm}$, the injection pressure of 3 injection wells increased and that of one injection well decreased after PMs injection, and its value increased by $2.5 \mathrm{MPa}, 5.0 \mathrm{MPa}, 1.0 \mathrm{MPa}$ and decreased by $1.0 \mathrm{MPa}$ as shown in Figure 12B. The average injection pressure of a single well-increased by $1.9 \mathrm{MPa}$, and the average thickness of the water-absorbing layer increased by $2.81 \mathrm{~m}$.

For the injection wells after the PMs' injection, the injection pressure significantly increased and the thickness of the water-absorbing layer significantly increased. These phenomena indicate that the PMs effectively plug the highpermeability channel in the reservoir, and significantly meliorate the characteristic of non-uniform water-absorbing. In the pilot test, the water-flooding conditions improved significantly after PMs' injection, and the application of PMs for in-depth profile control has a significant effect. The dynamic data of the injection wells shows the increased margin of average injection pressure and average water absorbing layer thickness for the injection wells using the PMs with a calibration diameter of $300 \mathrm{~nm}$ is larger than the injection wells using the PMs with a calibration diameter of $800 \mathrm{~nm}$. It indicated that, for the injection wells in the pilot test area, the PMs with a calibration diameter of $300 \mathrm{~nm}$ are better than the PMs with a calibration diameter of $800 \mathrm{~nm}$.

\section{Production Well Performance Evaluation}

The application of PMs for in-depth profile control is used mainly to improve the volumetric sweep efficiency of waterflooding (Raffa et al., 2016). When the high-permeability channel is plugged by PMs, the water will flow around, and then the swept volume of water-flooding will increase. Therefore, the oil layers that have not been swept before will be swept. In turn, oil production will increase. However, not all the oil production of production wells will increase after PMs' injection. It depends on many factors. The high-permeability channels in the reservoir can be plugged by the PMs, but are not plugged forever. The PMs will gradually cease to be in effect with water continually flooding. That is to say, there is a validity period for PMs plugging high-permeability channels. So, the validity period can be used as one of the parameters to evaluate the plugging ability of PMs. Other evaluation parameters include the success ratio, oil increment, and non-uniformity coefficient of liquid production and water cut.

For the production wells in the pilot test area, after using the PMs for in-depth profile control, the oil production of 19 wells out of the 42 wells increased, and the success ratio of in-depth profile control was $45.3 \%$. The average daily liquid production of a single well-increased from 5.8 to $6.7 \mathrm{t} / \mathrm{d}$, and the average water cut of a single well-decreased from 60.6 to $50.2 \%$. The non-uniformity coefficient of liquid production decreased from 0.66 to 0.59 , and the non-uniformity coefficient of water cut decreased from 0.45 to 0.4 . The validity period and total oil production increment of single wells are shown in Figure 14. For all the response production wells, the maximum and minimum validity period was $371 \mathrm{~d}$ and $42 \mathrm{~d}$, respectively, and the average validity period was $151 \mathrm{~d}$. The total oil production increment of production wells was $3,136.9 \mathrm{t}$, of which the maximum oil production increment of single wells was $437 \mathrm{t}$, and the minimum oil production increment of single wells was $21.8 \mathrm{t}$. 

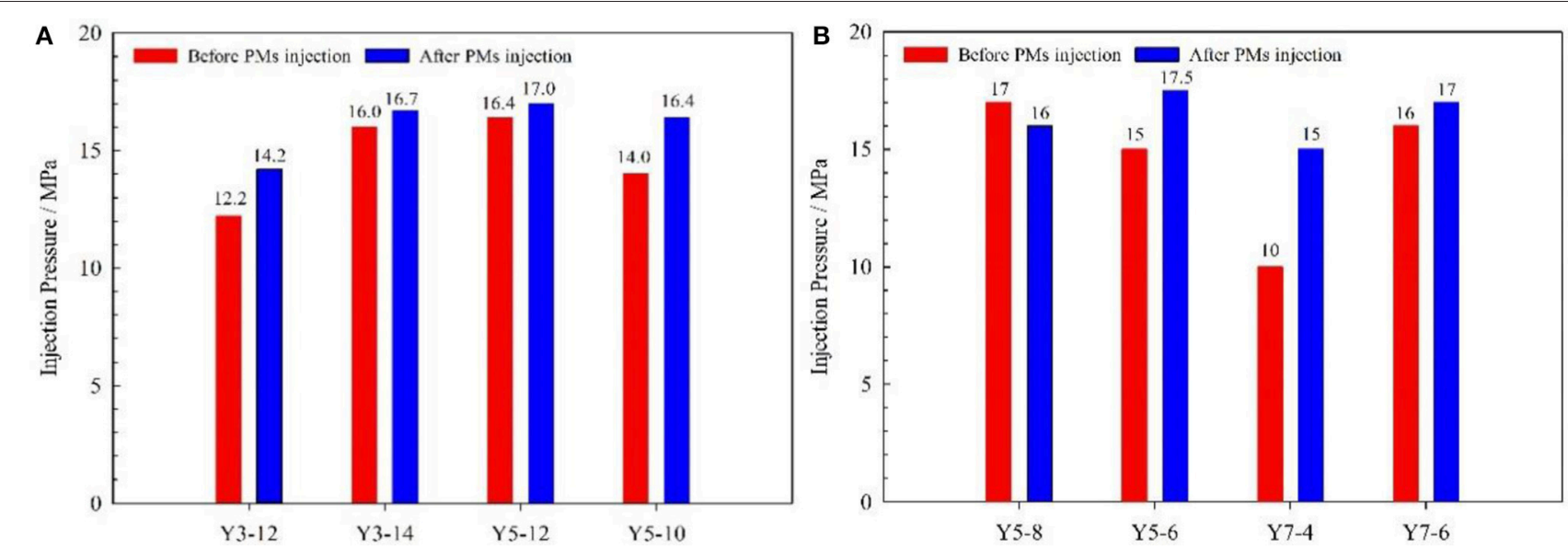

FIGURE 12 | Injection pressure before and after PMs injection. (A) The calibration diameter is $800 \mathrm{~nm}$; (B) The calibration diameter is $300 \mathrm{~nm}$.

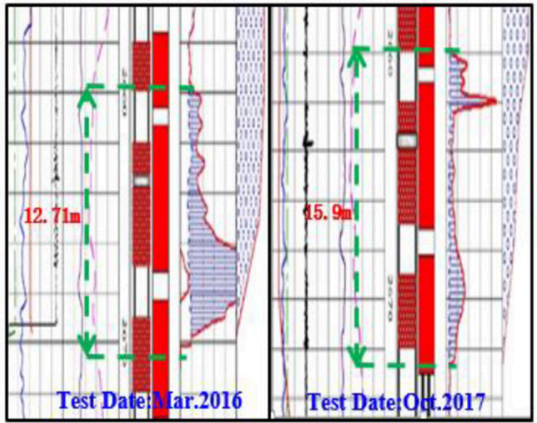

Y5-8

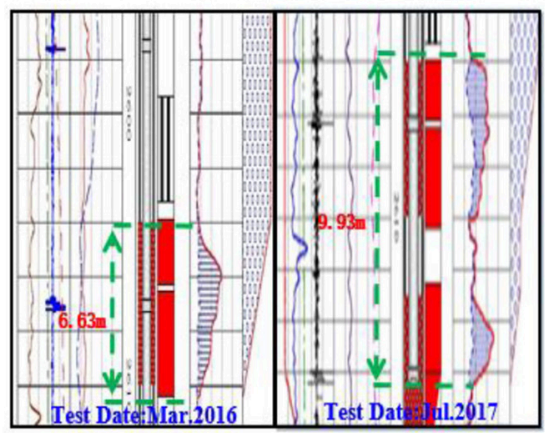

Y3-14

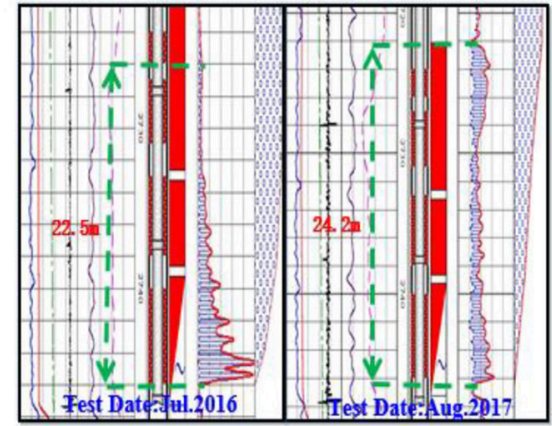

Y7-4

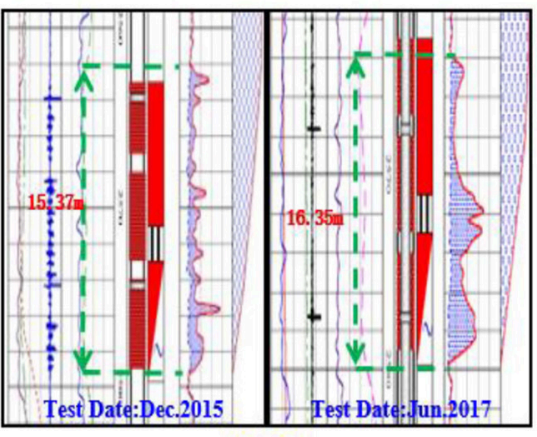

Y5-12

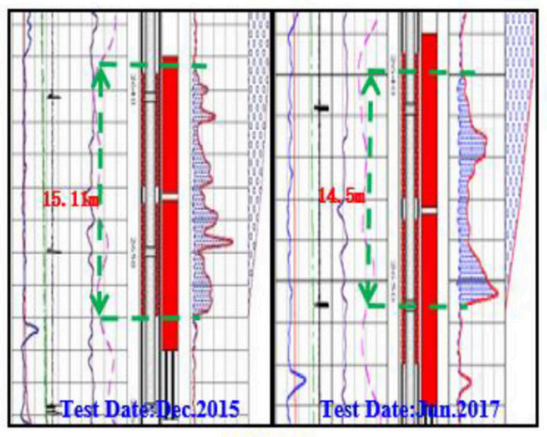

Y5-10

FIGURE 13 | Results of the water injection profile test before and after the PMs injection.

After the PMs were injected into the pilot test, the production conditions of production wells improved, and the oil production increased significantly.

For the 23 production wells using the PMs with a calibration diameter of $800 \mathrm{~nm}$, the oil production of 11 wells out of the 23 wells increased, and the success ratio of in-depth profile control was $47.8 \%$. The average daily liquid production of single wells increased from 5.2 to $6.2 \mathrm{t} / \mathrm{d}$, and the average water cut of single wells decreased from 58.3 to $55.6 \%$. The non-uniformity coefficient of liquid production decreased from 0.63 to 0.56 , and the non-uniformity coefficient of water cut decreased from 0.51 to 0.45 . The validity period and total oil production increment of single wells are shown in Figure 14A. For all the response production wells, the maximum and minimum validity period was $371 \mathrm{~d}$ and $52 \mathrm{~d}$, respectively, and the average validity period was $150 \mathrm{~d}$. The total oil production increment of production wells 
TABLE 5 | Data of the water injection profile test before and after the PMs injection.

\begin{tabular}{|c|c|c|c|c|c|}
\hline \multirow[t]{2}{*}{ Well } & \multirow[t]{2}{*}{ Particle size (nm) } & \multicolumn{2}{|c|}{ Before PMs injection } & \multicolumn{2}{|c|}{ After PMs injection } \\
\hline & & Test time & $\operatorname{TWAL}^{\mathrm{a}}(\mathrm{m})$ & Test time & TWAL $^{a}(m)$ \\
\hline Y3-14 & 800 & 2016.03 & 6.63 & 2017.07 & 9.91 \\
\hline Y5-10 & & 2015.12 & 15.11 & 2017.06 & 14.50 \\
\hline Y5-12 & & 2015.12 & 15.37 & 2017.06 & 16.35 \\
\hline Y5-8 & 300 & 2016.03 & 12.71 & 2017.10 & 15.90 \\
\hline \multirow[t]{2}{*}{ Y7-4 } & & 2016.07 & 22.50 & 2017.08 & 24.20 \\
\hline & Average value & & 14.46 & & 16.17 \\
\hline
\end{tabular}

a Thickness of water-absorbing layer.
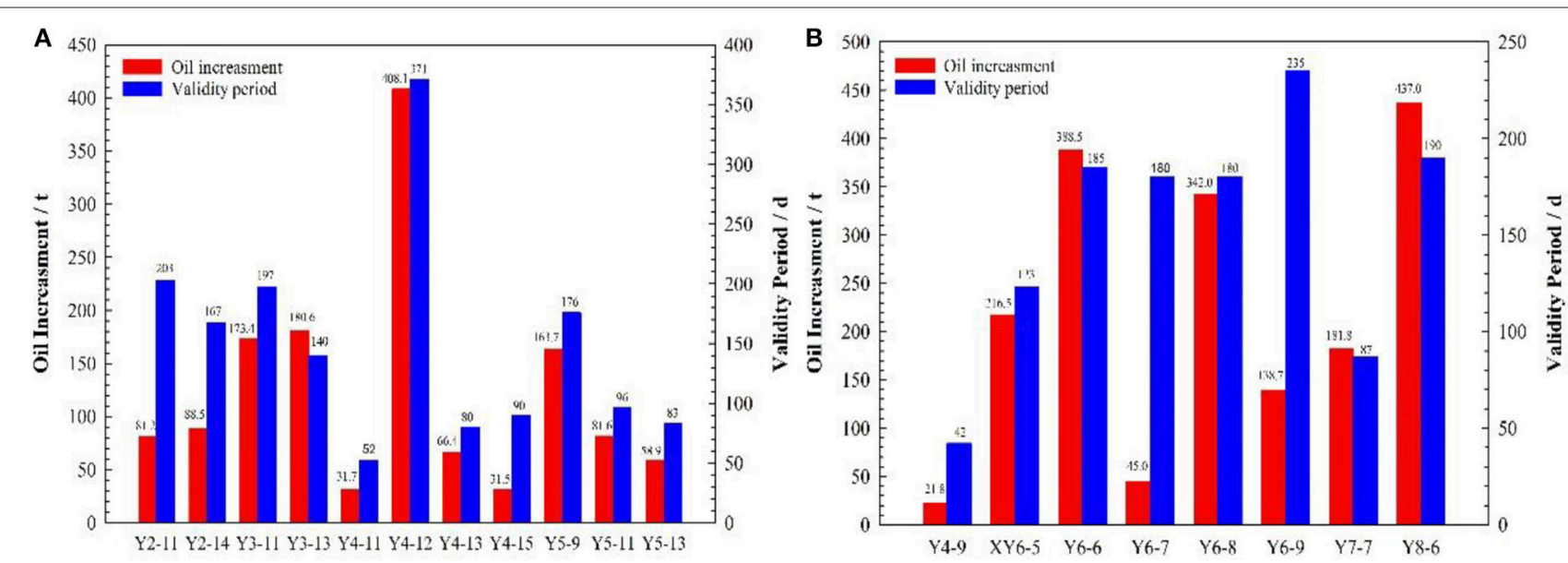

FIGURE 14 | Oil production increment and validity period for production wells. (A) The calibration diameter is $800 \mathrm{~nm}$; (B) The calibration diameter is $300 \mathrm{~nm}$.

was $1,365.6 \mathrm{t}$, of which the maximum oil production increment of single wells was $408.1 \mathrm{t}$, and the minimum oil production increment of single wells was $31.5 \mathrm{t}$.

For the 21 production wells using the PMs with a calibration diameter of $300 \mathrm{~nm}$, the oil production of eight wells out of the 21 wells increased, and the success ratio of in-depth profile control was $38.1 \%$. The average daily liquid production of single wells increased from 6.2 to $7.3 \mathrm{t} / \mathrm{d}$, and the average water cut of single wells decreased from 61.6 to $47.8 \%$. The non-uniformity coefficient of liquid production decreased from 0.72 to 0.61 , and the non-uniformity coefficient of water cut decreased from 0.42 to 0.33 . The validity period and total oil production increment of single wells are shown in Figure 14B. For all the response production wells, the maximum and minimum validity period was $235 \mathrm{~d}$ and $42 \mathrm{~d}$, respectively, and the average validity period was $153 \mathrm{~d}$. The total oil production increment of production wells was $1,771.3 \mathrm{t}$, of which the maximum oil production increment of single wells was $437 \mathrm{t}$, and the minimum oil production increment of single well was $21.8 \mathrm{t}$.

For the production well after the PMs injection, the average daily liquid production of single wells significantly increased, and the water cut, the non-uniformity coefficient of liquid production, and the non-uniformity coefficient of water cut significantly decreased. This phenomenon shows that the efficiency of water-flooding has been significantly improved. Combined with other evaluation parameters, such as the success ratio, validity period, and oil increment, the evaluation results indicate that the application of PMs for in-depth profile control in the pilot test area was very successful. Comparing the dynamic data of production wells using the PMs with a calibration diameter of $800 \mathrm{~nm}$ and with a calibration diameter of $300 \mathrm{~nm}$, after PMs' injection, the performance evaluation parameters of the wells using the PMs with a calibration diameter of $300 \mathrm{~nm}$ are better than the wells using the PMs with a calibration diameter of $800 \mathrm{~nm}$. The total oil increment and average validity period for the production wells using the PMs with a calibration diameter of $300 \mathrm{~nm}$ are larger than the production wells using the PMs with a calibration diameter of $800 \mathrm{~nm}$, but the success ratio of indepth profile control is the opposite. These evaluation parameters indicate that, for the production wells in the pilot test area, the PMs with a calibration diameter of $300 \mathrm{~nm}$ are better than the PMs with a calibration diameter of $800 \mathrm{~nm}$.

After the application of PMs in the pilot test area for indepth profile control, the production conditions of injection wells and production wells improved significantly. For the production wells, the water cut decreased, and the oil production increased. For the injection wells, the characteristic of nonuniform water-absorbing profile was improved. For the pilot 
test area, the efficiency of water-flooding improved significantly. These characteristics indicate that the PMs can be used for in-depth profile control in ultralow permeability oil reservoirs. Comparing the dynamic data of production wells and injection wells using the PMs with a calibration diameter of $800 \mathrm{~nm}$ and with a calibration diameter of $300 \mathrm{~nm}$, it indicates that, for the pilot test area, PMs with a calibration diameter of $300 \mathrm{~nm}$ are more suitable than the PMs with a calibration diameter of $800 \mathrm{~nm}$.

\section{CONCLUSION}

This paper reports on a field application case of nanoscale PMs for in-depth profile control in an ultralow permeability oil reservoir. In the paper, the PMs with calibration diameters of 300 and $800 \mathrm{~nm}$ were selected, and evaluation experiments were done to ensure their properties. Then, the performance of PMs in the pilot test area was evaluated, and the more suitable PMs size was determined for the pilot test area. The major conclusions that could be drawn from this study are as follows:

(1) Laboratory experiment results indicate that the PMs have a good capacity of swelling and plugging. More specifically, for the PMs with a calibration diameter of $300 \mathrm{~nm}$, the final equilibrium swelling ratio is $56.2 \mathrm{~nm} \cdot \mathrm{nm}^{-1}$, and the maximum resistance coefficient of the blocking rate after swelling are 3.7 and $70.31 \%$, respectively. For the PMs with a calibration diameter of $800 \mathrm{~nm}$, the final equilibrium swelling ratio is $49.4 \mathrm{~nm} \cdot \mathrm{nm}^{-1}$, and the maximum resistance coefficient of the blocking rate after swelling are 3.5 and $71.42 \%$, respectively.

(2) Comparing the dynamic data of well groups using the PMs with a calibration diameter of $800 \mathrm{~nm}$ and with a calibration diameter of $300 \mathrm{~nm}$, it indicates that, for the pilot test area,

\section{REFERENCES}

Afeez, O. G., Radzuan, J., and Muhammad, A. M. (2018). Recent advances and prospects in polymeric nanofluids application for enhanced oil recovery. J. Ind. Eng. Chem. 66,1-19. doi: 10.1016/j.jiec.2018.05.020

AfzaliTabar, M., Alaei, M., Bazmi, M., Ranjineh Khojasteh, R., KoolivandSalooki, M., Motiee, F.,et al. (2017) Facile and eonomical preparation method of nanoporous graphene/silica nanohybrid and evaluation of its pickering emulsion properties for chemical enhanced oil recovery (C-EOR). Fuel 206, 453-466. doi: 10.1016/j.fuel.2017.05.102

Asif, M., and Muneer, T. (2007). Energy supply, its demand and security issues for developed and emerging economies. Renew. Sustain. Energy Rev. 11, 1388-1413. doi: 10.1016/j.rser.2005.12.004

Dai, C., Liu, L., Zou, C., You, Q., Yang, S., Zhao, M., et al. (2017). Investigation on matching relationship between dispersed particle gel (DPG) and reservoir pore-throats for in-depth profile control. Fuel 207, 109-120. doi: 10.1016/j.fuel.2017.06.076

Dai, C. L., You, Q., and Fulin Z. (2010). In-depth profile control technologies in China-a review of the state of the art. Petrol. Sci. Technol. 28, 1307-1315. doi: 10.1080/10916460903419164

Diwu, P. X., Liu, T. J., You, Z. J., Jiang, B. Y., and Zhou, J. (2018). Effect of low velocity non-darcy flow on pressure response in shale and tight oil reservoirs. Fule 216, 398-406. doi: 10.1016/j.fuel.2017.11.041
PMs with a calibration diameter of $300 \mathrm{~nm}$ are more suitable than the PMs with a calibration diameter of $800 \mathrm{~nm}$.

(3) The performance evaluation results indicate that the PMs can be used for in-depth profile control in ultralow permeability oil reservoirs. Specifically, after the application of PMs in the pilot test area for in-depth profile control, for the production wells, the water cut decreased, and the oil production increased. For the injection wells, the characteristic of non-uniform water-absorbing profile improved. For the pilot test area, the efficiency of waterflooding improved significantly.

\section{DATA AVAILABILITY STATEMENT}

The raw data supporting the conclusions of this article will be made available by the authors, without undue reservations.

\section{AUTHOR CONTRIBUTIONS}

$\mathrm{GH}$ participated in the design of the manuscript and drafted the manuscript. GH, WZ, and YJ came up with ideas for the manuscript. $\mathrm{XY}$ and $\mathrm{JZ}$ carried out experiments. XY, GH, and TL analyzed experimental results. JZ and $\mathrm{GH}$ evaluated the performance of PMs in the pilot test area. TL and $\mathrm{JH}$ revised the manuscript. All authors contributed to the article and approved the submitted version.

\section{ACKNOWLEDGMENTS}

The authors would like to acknowledge financial support from the National Science and Technology Major Projects (2017ZX05009004).
Fletcher, A. J. P., Flew, S., Forsdyke, I. N., Morgan, J. C., Rogers, C., and Suttles, D. (1992). Deep diverting gels for very cost-effective waterflood control. J. Pet. Sci. Eng. 7, 33-43. doi: 10.1016/0920-4105(92)90006-M

Hua, Z., Lin, M., Dong, Z., Li, M., Zhang, G., and Yang, J. (2014). Study of deep profile control and oil displacement technologies with nanoscale polymer microspheres. J. Colloid Interf. Sci. 424, 67-74. doi: 10.1016/j.jcis.2014. 03.019

Hua, Z., Lin, M., Guo, J., Xu, F., Li, Z., and Li, M. (2013). Study on plugging performance of crosslinked polymer microspheres with reservoir pores. J. Pet. Sci. Technol. 105.70-75. doi: 10.1016/j.petrol.2013. 03.008

Ji, J. Q., Zeng, C. L., and Ke, Y. C. (2017). Preparation of poly (acrylamideco-acrylic acid)/silica nanocomposite microspheres and their performance as a plugging material for deep profile control. J. Appl. Polymer Sci. 134:45502. doi: 10.1002/app.45502

Jia, Y. Q., Yang, H. E., Cheng, C., Li, Z. P., Hou, G. G., Yuan, X. Y., et al. (2019). Field application and performance evaluation of polymer microsphere profile control in low permeability oil reservoir. ADIPEC SPE. 1-12. doi: 10.2118/197198-MS

Jia, Y. Q., Zheng, M. K., Yang, H. E., and Zhou, G. Q. (2018). Optimization of operational parameters for deep displacement involving polymer microspheres in low permeability reservoirs of changqing oilfield. Petrol. Drill. Tech. 46, 75-82. doi: 10.11911/syztjs.2018030 
Kang, W. L., Hu, L. L., Zhang, X. F., Yang, R. M., Fan, H. M., and Geng, J. (2015). Preparation and performance of fluorescent polyacrylamide microspheres as a profile control and tracer agent. Petrol. Sci. 12, 483-491. doi: 10.1007/s12182-015-0042-9

Kawaguchi, H. (2000). Functional polymer microspheres. Prog. Polymer Sci. 25, 1171-1210. doi: 10.1016/S0079-6700(00)00024-1

Lei, G. L., and Zheng, J. P. (2007). Composing of pore scale polymer microsphere and its application in improving oil recovery by profile control. J. China Univ. Petrol. 1, 87-90. doi: 10.1631/jzus.2007.B0507

Li, Y. X., Liu, Y. Z., Bai, B. J., and Liu, G. H. (1993). Research of expansion grain chemical for water shut-off and profile control. Oil Drill. Prod. Technol. 3, 65-68. doi: 10.1002/smll.200901759

Liang, S. C., Lu, X., Liang, D., and Wen, H. B. (2016). A study on matching relationship of polymer microsphere size. J. Southwest Petrol. Univ. 38, 140-145. doi: 10.11885/j.issn.1674-5086.2013.11.12.03

Lin, M., Zhang, G., Hua, Z., Zhao, Q., and Sun, F. (2015). Conformation and plugging properties of crosslinked polymer microspheres for profile control. Colloids Surf A Physicochem. Eng. Aspects 477, 49-54. doi: 10.1016/j.colsurfa.2015.03.042

Liu, C., Liao, X., Zhang, Y., Chang, M. M., Mu, C. R., Li, T. L., et al. (2017). “Field application of polymer microspheres flooding: a pilot test in offshore heavy oil reservoir," in SPE Annual Technical Conference and Exhibition (San Antonio, TX). doi: 10.2118/158293-MS

Liu, T. J., Liu, W. X., Diwu, P. X., Hu, G. X., Xu, T., Li, Y. Q., et al. (2020). Modeling tracer flow characteristics in different types of pores: visualization and mathematical modeling. Comput. Model. Eng. Sci. 123, 1205-1222. doi: $10.32604 / \mathrm{cmes} .2020 .08961$

Liu, Y. L., Yuan, X., Zhou, J., Fu, N., and Zhao, J. (2018). Research of profile control agent for low permeability reservoir and plugging performance. Petrochem. Ind. Appl. 37, 6-11+32. doi: 10.3969/j.issn.1673-5285.2018.01.002

Mehta, R. N., More, U., Malek, N., Chakraborty, M., and Parikh, P. A. (2015). Study of stability and thermodynamic properties of water-in-diesel nanoemulsion fuels with nano-Al additive. Appl. Nanosci. 5, 891-900. doi: 10.1007/s13204-014-0385-3

Nandwani, S., Malek, N. I., Chakraborty, M., and Gupta, S. (2020). Insight into the application of surface-active ionic liquids in surfactant based enhanced oil recovery processes - a guide leading to research advances. Energy Fuels. 34, 6544-6557. doi: 10.1021/acs.energyfuels.0c00343

Pu, W. F., Liu, R., Peng, Q., and Du, D. J. (2016). Amphiphilically modified chitosan copolymer for enhanced oil recovery in harsh reservoir condition. J. Ind. Eng. Chem. 37, 216-223. doi: 10.1016/j.jiec.2016.03.034

Raffa, P., Broekhuis, A. A., and Picchioni, F. (2016). Polymeric surfactants for enhanced oil recovery: a review. J. Petrol. Sci. Eng. 145, 723-733. doi: 10.1016/j.petrol.2016.07.007

Sang, Q., Li, Y., Yu, L., Li, Z., and Dong, M. (2014). Enhanced oil recovery by branched-preformed particle gel injection in parallel-sandpack models. Fuel 136, 295-306. doi: 10.1016/j.fuel.2014.07.065

Sun, H. Q., Wang, T., and Xiao, J. H. (2006). Novel technique of in-depth profile control step by step by polymer microspheres. Petrol. Geol. Recov. Efficiency 4, 77-79. doi: 10.3969/j.issn.1009-9603.2006.04.024

Tu, W. X., and Wang, C. G. (2011). Pore-throat-scale composite microspheres of inorganic-organic polymer: a novel type of profile-control and oil-displacement agent. China Offshore Oil Gas 23, 243-246. doi: 10.3969/j.issn.1673-1506.2011.04.007

Wang, T., Xiao, J. H., Sun, H. Q., Cao, Z. Q., and Song, D. F. (2006). Study on the size influence factors and the plugging properties of polymer microspheres. Petrol. Geol. Recov. Efficiency 4, 80-82. doi: 10.3969/j.issn.1009-9603.2006.04.025

Wu, T. J., Zheng, M. K., Zhou, Z. P., Yang, H. E., and Cao, R. R. (2018). New method for plugging performance evaluation of polymeric nanospheres in low permeability reservoir. Fault Block Oil Gas Field 25, 498-501. doi: 10.6056/dkyqt201804019

Yang, H. B., Kang, W. L., Wu, H. R., Yang, Y., Zhou, Z., Wang, P. X., et al. (2017a). Stability, rheological property and oil-displacement mechanism of a dispersed low-elastic microsphere system for enhanced oil recovery. RSC Adv. 7, 8118-8130. doi: 10.1039/C6RA26849H

Yang, H. B., Kang, W. L., Yin, X., Tang, X. C., Song, S. Y., AliLashari, Z., et al. (2017b). Research on matching mechanism between polymer microspheres with different storage modulus and pore throats in the reservoir. Powder Technol. 313, 191-200. doi: 10.1016/j.powtec.2017. 03.023

Zeng, Q. Q., Meng, Q. C., Liu, Y., Wang, L., Wang, X., and Wang, F. (2012). Application of polymer microspheres deep profile control technique in complex fault block reservoir. Oil Drill. Prod. Technol. 34, 91-94. doi: 10.3969/j.issn.1000-7393.2012.05.024

Zhang, X. L., and Zhou, X. J. (2008). Experimental study on profile control and flooding with polymer elastic microsphere emulsion. Oil Drill. Prod. Technol. 5, 89-92. doi: 10.3969/j.issn.1000-7393.2008.05.021

Zhao, G., Dai, C., and Zhao, M. (2014). Investigation of the profile control mechanisms of dispersed particle gel. PLOS ONE 9:e100471. doi: 10.1371/journal.pone.0100471

Zhao, G., You, Q., Tao, J. P., Gu, C. L., Ma, L. P., and Dai,. C. L. (2018). Preparation and application of a novel phenolic resin dispersed particle gel for in-depth profile control in low permeability reservoirs. J. Petrol. Sci. Eng. 161, 703-714. doi: 10.1016/j.petrol.2017.11.070

Zhou, Z., Zhao, J., Zhou, T., and Huang, Y. (2017). Study on in-depth profile control system of low-permeability reservoir in block $\mathrm{H}$ of Daqing oil field. J. Petrol. Sci. Eng. 157, 1192-1196. doi: 10.1016/j.petrol.2017.08.008

Conflict of Interest: YJ was employed by the Oil \& Gas Technology Research Institute of Changqing Oilfield Company and the JZ was employed by the Beijing Jinshi Liyuan Science Co., Ltd.

The remaining authors declare that the research was conducted in the absence of any commercial or financial relationships that could be construed as a potential conflict of interest.

Copyright (C) 2020 Hou, Zhao, Jia, Yuan, Zhou, Liu and Hou. This is an open-access article distributed under the terms of the Creative Commons Attribution License (CC $B Y)$. The use, distribution or reproduction in other forums is permitted, provided the original author(s) and the copyright owner(s) are credited and that the original publication in this journal is cited, in accordance with accepted academic practice. No use, distribution or reproduction is permitted which does not comply with these terms. 